\title{
Balkanologie
}

Balkanologie Revue d'études pluridisciplinaires

Vol. VIII, $n^{\circ} 1$ | 2004

Volume VIII Numéro 1

\section{Sorties de guerres et de violence}

\section{Dejan Dimitrijevic}

\section{OpenEdition}

Journals

Édition électronique

URL : http://journals.openedition.org/balkanologie/2072

DOI : 10.4000/balkanologie.2072

ISSN : 1965-0582

\section{Éditeur}

Association française d'études sur les Balkans (Afebalk)

\section{Édition imprimée}

Date de publication : 1 juin 2004

ISSN : 1279-7952

\section{Référence électronique}

Dejan Dimitrijevic, «Sorties de guerres et de violence », Balkanologie [En ligne], Vol. VIII, $n^{\circ} 1$ | 2004, mis en ligne le 21 janvier 2010, consulté le 17 décembre 2020. URL : http://journals.openedition.org/ balkanologie/2072 ; DOI : https://doi.org/10.4000/balkanologie.2072

(C) Tous droits réservés 


\title{
SORTIES DE GUERRES ET DE VIOLENCE
}

\author{
Dejan Dimitrijevic*
}

La fin de la violence n'est pas effective et immédiate dès lors que la fin des hostilités a été officiellement décrétée. Sortir de la violence est un processus, c'est réordonner le monde. Et c'est ce processus que nous voulons analytiquement pointer, car il ne lui est pas accordé une place suffisante dans nos disciplines. Nous constatons une propension beaucoup plus grande à interroger et à médiatiser les causes des conflits, qu'à se pencher sur ce processus de ré-agencement du monde social concerné. C'est pourtant un champ d'investigation essentiel pour tenter de mieux comprendre les enjeux contemporains : c'est là que se construisent le présent et l'avenir, mais aussi le passé ; la question de la maîtrise du passé est ici primordiale.

Depuis longtemps, les sciences sociales, notamment l'anthropologie et l'histoire, mais aussi la philosophie posent la question des usages sociaux du passé. Ce travail se fait le plus souvent au travers des thèmes tels que la " tradition " ou la " mémoire ", par exemple. Eric Weil, Jean Pouillon, Eric Hobsbawm, Paul Ricoeur, Gérard Lenclud, Marcel Detienne, Reinhart Koselleck, parmi bien d'autres, leur accordent une place centrale dans leurs travaux. En 2001, la revue Enquête a consacré l'expression " les usages politiques du passé ", en titrant ainsi un numéro passionnant. Nous voyons maintenant ici et là apparaître ce titre sous la variante " les usages sociaux du passé " en intitulé de cours et de séminaires ; notamment en anthropologie. Le succès du titre est compréhensible vue la richesse thématique qu'il permet d'aborder, même si nous pourrions discuter de la connotation fonctionnaliste qui en réduit la portée. 
Quoi qu'il en soit, avec le champ de la sortie de violence, nous nous inscrivons évidemment dans ce débat, mais pour l'aborder bien en amont : avant de faire un quelconque usage du passé, il faut le fabriquer (pour aller vite), lui donner un sens. En soumettant à l'examen cette période où le présent devient passé, nous avons voulu voir ce qui régissait cette transformation, et ce qu'on pouvait y lire.

Pour éviter le risque de se noyer dans un sujet trop vaste, nous abordons le thème de la violence par une problématique à mon sens trop peu mise en évidence : la " sortie de violence ", ou comment les individus et les sociétés reconstruisent leur présent et leur futur, mais aussi immanquablement le passé proche (celui du conflit) et le passé éloigné. Cette reconstruction a des implications sociales, politiques, économiques, culturelles et idéologiques, aux échelles du local et du global. Nous considérons les procédures et les modalités de pacification dans plusieurs contextes sociaux, politiques et géographiques. Des situations issues des guerres des années 1990 dans l'espace yougoslave, de l'Insurrection bulgare d'avril 1876, et de la guerre civile du Sonderbund qui divisa la Suisse, en 1847.

Les cas étudiés pointent plusieurs aspects de la sortie de violence. Les déplacements de population accompagnent malheureusement couramment les confits armés. Au travers du cas de Mostar, Stéphanie Rolland montre la complexité et les difficultés de la situation des déplacés, ainsi que les conséquences sociale, politique et humaine de cette tragédie aux multiples enjeux.

Dans, sa contribution " Pas coupables, mais responsables. Construire la Suisse après la guerre civile (1847) ", Irène Herrmann propose une étude critique du " modèle " suisse et montre qu'il n'est pas transposable sur d'autres terrains, bien qu'il soit souvent proposé comme type idéal de la coexistence de la résolution des conflits. La gestion de l'après-guerre civile suisse de 1847 dévoile comment s'est historiquement constituée la " tradition d'accommodement " helvétique.

Mon texte aborde la question du traitement du passé. Conformément à une politique nationale influencée par les institutions internationales, les autorités serbes œuvrent à la transformation du Mémorial 21 Octobre de Kragujevac dans le sens d'une promotion des valeurs de paix et de tolérance. Cependant, inévitablement investi par la mémoire collective serbe, ce projet n'échappe pas aux tensions et aux contradictions de la société serbe, qui est loin d'être pacifiée car elle est structurée par un passé conflictuel.

Bernard Lory propose une relecture de l'événement de l'Insurrection d'Avril (1876) essentiel dans l'historiographie nationale bulgare. Il montre qu'il existait dans les Balkans des modalités autochtones de gestion de conflits et qu'il existe des ressources locales pour gérer et prévenir les conflits. 
Isabelle Delpla discute l'idée, largement répandue, qu' « il n'y a pas de paix sans justice " (pénale) et que la justice peut et doit contribuer à la réconciliation. La confrontation de cette idée avec la situation effective des pays concernés pointe le décalage entre les déterminations normatives des juristes internationaux et les attentes des victimes et de leur famille, plus soucieuses, par exemple, de la recherche des disparus. In fine, c'est la question de la contribution de la justice pénale internationale à un processus de reconstruction qui est posée. Ce processus de reconstruction qui traverse l'ensemble des contributions, et s'avère appartenir à une temporalité longue. 